\title{
Editorial: Fashion communication: Between tradition and digital transformation
}

\author{
Nadzeya Kalbaska, USI - Università della Svizzera italiana, Faculty of Communication Sciences* \\ Teresa Sádaba, ISEM Fashion Business School \\ Lorenzo Cantoni, USI - Università della Svizzera italiana, Faculty of Communication Sciences \\ *Corresponding author: nadzeya.kalbaska@usi.ch
}

We are happy and thrilled to introduce this thematic section of Studies in Communication Sciences (SComS), devoted to Fashion Communication. It was about two years ago when we first discussed the idea in Madrid: then we got the approval by SComS Editors, published the call, and eventually secured the outstanding collection of papers you have in your hands (or on your screen). A long and enriching journey, full of interactions, conversations, views and reviews, a journey that makes the scholar's work so fascinating (even if, sometimes, not that fashionable).

This editorial has two main goals.

On one side, it aims to provide a helicopter view on the topic, exploring fashion as (also) communication (par. 1); how communication and its media have been intertwined with fashion and its related industries and practices (par. 2); how recent digital transformation has impacted fashion, making room for new communication affordances and business models (par. 3).

On the other side, it presents the collected articles, placing them on the abovesketched map of fashion communication (par. 4): their diversity and complementary nature is for sure a great richness for this issue of SComS and for all its readers.

\section{Fashion is (also) communication}

All human beings are born unclad, but need to dress in order to protect from external agents - cold, heat, sun, rain, snow, sand, surfaces - and because of modesty all human communities cover their genitalia.
The way we dress ourselves goes well beyond functional needs and the protection of one's own intimacy. It is a major way through which we express ourselves and communicate to others who we are or who we would like to be. While covering our body with clothes, accessories and makeup, we unveil - through them - our deepest thoughts, values, desires... Or they betray us!

We enter in a relationship with other human beings and with our communities at large (also) through the way in which we dress. First through the way in which we are adorned by our parents, and, later once grown-up - through the clothes we choose to wear. Our visual appearance accompanies, and even precedes us. It helps us to communicate who we are. Our identity is somehow connected with the way we dress and position ourselves within the wider paradigm of (un)acceptable options and practices.

The etymology of Cosmesis links it with

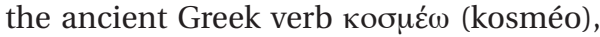
which means: "to put order." This is also the case with Cosmos, which means an ordered Universe. Terms related to these were used to refer to the adornment of the human body and to house decor. The connection between (i) our skin - where cosmetics are used; (ii) the way in which we cover it - apparel; and (iii) the way in which we shelter it - home, is apparent in the Latin terms habitus (habit and dress) and habito (living), both originating from habere - "to have." Interestingly their frequentative form, what I have regularly, is used to refer to our way of behaving ( $h a b$ it, socially accepted customs), of dressing 
(e.g.: in Italian: abito), and of living (e.g.: in Italian: abitazione).

Those "ways of," which express and communicate in a visible way the invisible human mind and spirit, are closely connected with culture. Basing ourselves on the Latin verb "colo" (meaning "looking after," "caring"), culture can be seen from the different perspectives of (i) cultivating our physical/natural environment (agri-culture); (ii) looking after ourselves and other human beings (in order to become well cultivated persons); and (iii) entering in relation to God (cult). If we look at those perspectives with relation to fashion we derive three layers for cosmetics and clothes, which (i) use available natural materials or create new artificial ones; (ii) are shaped and designed according to different culturally-linked styles and fashions; (iii) are particularly elaborated when in relation to the very meaning of human life - weddings, religious celebrations and cult, holidays, funerals...

The way we dress might be part of the intangible cultural heritage, which, according to the 2003 UNESCO Convention, encompasses “(...) (b) performing arts; (c) social practices, rituals and festive events; (...); (e) traditional craftsmanship" (UNESCO, 2003: art. 2). In summary: "We wear culture" as is suggested by the payoff of a major initiative by the Google Cultural Institute, aimed at digitally documenting fashion history and trends.

Based on these few suggestions, it becomes clear why fashion has been so frequently approached within semiotic and communication studies, offering endless opportunities to interpret human behavior and communicate relationships, as well as social values and practices.

If we delve deeper into the relationship between fashion and communication, we come across various angles that directly connect the two realms. Without being exhaustive, we can talk about the following aspects: (a) imitation as a form of leverage in fashion and as a formula for social cohesion and communication; (b) appearance and its relationship with reality in the fields of fashion and communication; (c) fashion as a means of com- munication and expression in itself; and (d) prescription and influence on the part of leaders within the realms of fashion and communication. Imitation, expression, prescription and appearance are all issues that are tackled in depth by communication theory, and that provide us with a direct explanation of the fashion phenomenon.

\subsection{Imitation}

First of all, and as a defining characteristic, fashion combines a unique dimension with a general appeal, in the sense that, through our dress sense and demeanor, we seek to gain social approval, on the one hand, and we aspire to distinguish ourselves through a unique appeal, on the other. Fashion, therefore, hinges together a desire to belong with a desire for personal expression; it combines a wish to avoid social isolation with a search for being different.

Georg Simmel, in his Philosophy of Fashion (1905), states that fashion is a constant feature in the history of our species because it satisfies two needs of all individuals: the need to depend on society, to belong and to fit into the group; and the need to set ourselves apart, affirming our personal identity, which tends towards differentiation, towards change and standing out from the rest.

Simmel declared that this integration of the social and individual realms takes place through imitation, given that in this manner, the individual has "the assurance of not standing alone in his or her actions" (1923, p. 60). Imitation is "the child of thought and thoughtlessness" and "it permits purposive and meaningful action even where nothing personal or creative is in evidence." Imitation is the hinge that makes the dynamics of fashion possible.

Gabriel Tarde, in Les lois de l'imitation (1890), explained that imitation is an elementary social phenomenon that creates unity within society, given that imitation does not exist on its own, we must imitate "something" and that "something" is a belief, a desire, an object. When imitating, we establish a copy of a model and a similarity, in whose respect a so- 
cial relationship is created. Consequently, Tarde argues that society began "on the day when one man first copied another."

According to these authors, the dynamics of fashion are sociologically stratified according to class. Simmel writes that "fashions are always class fashions, by the fact that the fashions of the higher strata of society distinguish themselves from those of the lower strata, and are abandoned by the former at the moment when the latter begin to appropriate them" (1923, p. 62). In Tarde's opinion, fashion is like "a continuous waterfall of imitation," where fashion is a social process of imitation in which the lower social classes seek to imitate the higher classes. This has been called the "trickle-down theory." Modern-day theorists such as Gilles Lipovetsky (1987) declare that the relationship between fashion and social classes and estates undoubtedly exists. He warns though that fashion cannot be reduced solely to this, because viewing it exclusively in these terms "leaves out an essential dimension of the phenomenon: the play of freedom inherent in fashion, possibilities of nuance and gradation, opportunities to adapt or reject innovations" (p. 45). Lipovetsky explains that, since the day of Chanel in the 1920s, fashion has no longer belonged solely to the élite, but has been extended throughout all the social classes. For Madame Coco, "if a fashion does not spread to the majority it has not succeeded." Furthermore, imitation does not always take place at the bottom looking upwards from a social point of view; it often takes place in the opposite direction.

Dick Hebdige (1988) illustrates this point by analyzing the case of the Vespa. The Vespa was created in Italy as a feminine counterpart for Harley Davidson, the quintessentially masculine motorbike linked to the rock movement. Piaggio dreamed up the idea of the scooter by thinking of a motorbike for women, but it was not very successful. It was not until the 1960s that the Mod movement (English followers of modern jazz, tailored suits) took off in England and appropriated the Vespa as its iconic symbol. In fact, the main reason this happened was because public transport ceased to operate relatively early in the evening, and Vespas were cheaper than cars. After a law was passed requiring at least one rear-view mirror on each motorbike, the Mods added large numbers of them to their bikes - it became customary to install more than ten - to mock the new law. Although the Vespa had a new target group, manufacturers were satisfied because it was coherent with their product: an urban customer with a friendlier image than the one Hollywood associated with the Harley.

This example reveals the meaning of products and their transformation, but also the need for identities, as shaped through icons of a highly symbolic and, therefore, communicative value.

In this respect, imitation is conceived as a mechanism for promoting social uniformity, but also as an entire educational process for individuals, a process whereby they adapt to their environment, enabling them to live in society. Fear of social isolation leads us to seek out this information and to adapt our tastes to new patterns.

\subsection{Appearance}

It is this fear of social isolation that public opinion studies refer to as the "Spiral of Silence," a theory propounded by Elisabeth Noelle-Neumann (1974). According to this political scientist, we adapt our behavior to predominant attitudes regarding what is considered acceptable and what is not. And who determines what is acceptable? According to Noelle-Neumann, the media contribute in a decisive manner when it comes to creating a climate of opinion that is favorable or unfavorable to a certain idea or form of behavior. The more widely this dominant version is disseminated, the more silent any individual dissenting voices become, which produces a "spiral of silence."

We might mention a fairy-tale here that refers to the spiral of silence and the question of dress sense: Hans Christian Andersen's The Emperor's New Clothes. In the story, two cunning tailors take advantage of an emperor's arrogance, and they convince him that they are capable of weaving a suit that can only be seen by highly 
intelligent people. When the tailors are simulating their work, the emperor's arrogance prevents him from saying what is really happening, out of a fear of being considered stupid. And this vanity leads him to parade up and down in front of his subjects, who, in turn, pretend to see the suit in order not to reveal their ignorance to their fellow onlookers. In the end it is an innocent child, free of prejudices and who has no need to demonstrate anything to anyone, who shouts out: the emperor has no clothes!

This tale illustrates another fundamental paradox of fashion and its communicative dimension: the tension between appearance and reality. This has to do with the public demonstration of a way of being and dressing and their relationship with the reality on which they are based. This is one of the most fascinating aspects of communication and it has guided the debate regarding knowledge and its communication since the time of Plato's cave.

Machiavelli, the master of political communication in the modern age, urged Lorenzo de Medici on by telling him: "Men judge generally more by the eye than by the hand." This recommendation led to an entirely new way of understanding social behavior, but it also pitted appearance against truth, when the latter should really guide the former. With our appearance we are already saying a great deal about who we are, and for this reason it is no trivial thing to dress one way or another according to the occasion and the function our dress-sense fulfills. We communicate through appearance. Julius Caesar's saying, as quoted by Plutarch, is famous: "Caesar's wife should not only be honest, but should be seen to be honest."

Whatever the case may be fashion is immersed in the realm of appearance to the extent that it seeks to cultivate appearance. As Peter Burke (1995) pointed out, the suit helps to 'fabricate' an identity through the power of image and the creation of appearances.

\subsection{Expression}

Third, as we pointed out in the first few lines of this introductory chapter, fashion and its relationship with semiotics leads to a direct link to the realm of communication. Fashion, as a channel for communication, has been analyzed by various researchers like Barthes (1973), Alison (1981), Davis (1994), Entwistle and Millet (2002), and Lotman (2011). For some, such as Alison (1981), fashion, understood in its widest sense - clothing, hairstyles, postures, ways of walking, etc. - has its own grammar and vocabulary, just like spoken languages. For others, such as Davis (1994), although we can think of fashion as a language, it is an ambiguous language, as in the case of music as a language. Davis, unlike Alison, argues that the idea of fashion as a language should be applied in a metaphorical rather than a literal sense.

Considering the power of image in fashion, it could be said that fashion as language is a visual language. Therefore, it is a nonverbal, universal language with many interpretation possibilities.

Tungate (2013) reflects on the expressive capacity of fashion when he explains that individuals do not purchase clothing; they purchase identity: "When clothes leave the factories where they are made they are merely 'garments' or 'apparel.' Only when the marketers get hold of them do they magically become 'fashion'” (2013, p. 11). For this reason, "it would be foolish of us to underestimate the importance of fashion in society. Clothes and accessories are expressions of how we feel, how we see ourselves - and how we wish to be treated by others" (2013, p. 11). And in this manner, thanks to its capacity to reflect what the individual is, feels or thinks, fashion helps to construct and convey our identity.

\subsection{Prescription and influence}

Finally, we might talk about the relationship between fashion and communication through an analysis of influence. Back in the 1940s, Paul Lazarsfeld and colleagues (1944) investigated the impact of personal relations in influence processes. In Decatur, Illinois, he carried out research in order to determine the level of influence to which the inhabitants of this Mid-West town were subjected, considering Decatur to be an average American town. With re- 
gard to aspects relating to their daily lives, Lazarsfeld sought to determine those opinions that were taken into account and those that led the inhabitants to take certain decisions. The aspects he tackled in his study were, therefore, the kind of things that come up in a daily chat: politics, cinema, marketing... and fashion. His findings led him to conclude that certain opinion leaders existed who operated at an informal level, almost unconsciously, amongst friends, family, colleagues and neighbors. For example, we might mention a mother's opinion about how her child should dress, a dinner conversation in which the participants talk about the mayor or a chat amongst friends about the latest Hollywood movie.

More recently, a study has revealed that one out of ten Americans tells the other nine how to vote, where to eat and what to buy (Keller \& Berry, 2003). That is to say, certain people exist among us who have a capacity to prescribe what we purchase, to influence our political views and tell us what we should wear tomorrow. These people are known as 'influentials.' A study published recently states: "influentials do not exercise high-level leadership like that of Churchill, nor that of a politician, and not even that of the social élite. Rather, their influence works at the opposite end of the spectrum: it is an almost invisible and certainly inconsistent influence, one that works at a face to face, daily, private and informal level" (Jove, 2011, p. 130).

Given the importance of these figures as generators of opinion, consumption and behavior, researchers have focused for some time now on detecting precisely who these influentials are and how they can be identified. In Germany in the 1980's, the magazine Der Spiegel was interested in "active consumers who set the standards for their communities," so it asked the Allensbach Institute to create a scale to identify them, to discover the characteristics of an influential. They defined a "personality strength scale" (Noelle-Neumann, 1983) associated with three attributes: (a) personification of certain values (who you are); (b) competence (what you know); and (c) strategic location, socially-speaking (whom you know). The higher the levels of personification, knowledge and social relations in a specific context relating to a certain matter, the higher the influence of the individual in question. In a very similar manner to these conclusions, Malcolm Gladwell, in The Tipping Point (2000), a book that has become a veritable classic amongst communication and fashion analysts, characterized influentials and attributed to them the capacity to generate social change. Change, according to Gladwell, works like an epidemic: the spread of new products or ideas penetrates society in the same way as a virus.

This US author began his popular book by citing an example of fashion within the footwear sector. He focused on Hush Puppies, a hard-wearing footwear brand that emerged in 1958 to meet the demands of the post-war generation. The brand was highly successful in the 1960s, but subsequently entered into terminal decline, to the point in which the brand's factories almost closed completely in the 1990s. However, a New York group suddenly started to wear the shoes, others copied them and these, in turn, were copied by others... The brand's image (a basset hound) appeared on the roof of a shop in New York's Soho neighborhood. In 1995 some 430000 pairs of shoes were sold. The following year, sales quadrupled and, subsequently, they continued to rise. Hush Puppies were brought back to life without the company having done anything.

Prescription, imitation, influence and personal relations: they all help to create a trend and determine its penetration within social life.

What doubt can there be that this set of factors is enhanced and achieves a whole new dimension with all the possibilities for interaction and spontaneity provided by the Internet? Indeed, the Internet strengthens mechanisms for selective perception and subjective interest, given that it empowers users to focus their search for information on aspects that are important to them. With the opportunities offered by the Internet, Lazarsfeld's concept of opinion leaders is brought back to life and endowed with a new dimension: 
Influentials are capable of obtaining and generating informative resources (SanMiguel et al., 2017) regarding their topic and can explain and distribute these through their personal relationships (via the social media, for example).

With the possibilities provided by the Internet, we can delve deeper into communicative relations. If, just a few decades ago, talking about communication meant talking about the influence of mass media, today, it is clear that communication also extends to the realm of personal relations.

It has also been demonstrated that influentials are more subject to information that appears in the traditional media regarding their topic of interest in this case fashion. In this respect, we can suppose that the new influentials consume more fashion magazines and are more alert to the advertising that appears in them.

A review of traditional communication theories, such as that of Lazarsfeld, which have gained new relevance thanks to the Internet, might also lead us to propose the idea that the relationship between communication and fashion - and the tensions that exist between them - may have also acquired a new shape in today's society.

\section{Communication (media) and fashion-related industries and practices}

For the dissemination and consumption of trends to be effective, it is essential that these should be communicated. Purchasing behavior can only be activated if the consumer previously knows and values the product. This awareness and these attributes must be deployed in the communication strategy.

Traditionally, the realm of communication, understood as a professional activity designed to serve fashion brands and companies, could be split into the following fields, at the very least:

, Corporate communication: positioning, identity, lobbies, relations with investors.

, Internal communication.
, External communication: advertising (various formats), campaigns, promotions, publicity, sponsorship, media relations.

, Public relations: institutional relations, events, patronage, protocol.

, Crisis communication.

, Social media.

Furthermore, due to the close relationship between fashion and communication, all manifestations of the communication strategy acquire a unique appeal within the realm of fashion. Fashion in itself has an expressive and communicative capacity, and many characteristic aspects have a communicative power. For instance, the product itself: labelling, packaging, product placement; the shop and its location, sales force, visuals or fashion shows with celebrities, designers, backstage...

However, in a changing communication environment, many of these areas of communication take on new meanings. Specifically, we might mention some changes that affect almost all of these communication facets. On one hand, the immediacy of new fashion business models and the immediacy facilitated by the technology employed by users has changed communication times and intervals and modified certain formulas, such as fashion shows, for example. On the other hand, the Internet has created hybrid models between communication and trade, models that have emerged as strong new players within the fashion market.

Whatever the case may be, and although the validity of certain traditional communication activities has been called into question, new opportunities and new ways of focusing on and reaching target groups have come to the fore.

\subsection{Fashion magazines}

\subsubsection{Historic overview}

One paradigmatic example of these developments is provided by fashion magazines. If fashion is a realm for innovation and imitation, it is the specialized fashion press that has been the engine that has helped the fashion phenomenon to become a reality. 
With the idea of propagating lifestyles and fashion through information and advertising, fashion magazines have witnessed and promoted the great trends and changes that have taken place within the industry. A considerable part of the importance of Paris as the cradle of fashion and worldwide model for elegance has to do with the fact that the first fashion publications available emerged in France.

In effect, one of the very first publications that could be considered a forerunner of the fashion magazine was Mercure Galant (renamed Mercure de France in 1714), the first French literary gazette. It was published between 1672 and 1724 (with a dormant interval between 1674 and 1677). Founded by the writer Jean Donneau de Vizé, it was aimed at members of the elegant French society in order to inform them about Court activities, artistic premières and new literary features, as well as offering songs, poems, anecdotes, society news and fashion reports. It played an important role in terms of promoting those establishments where the appropriate clothing items and accessories could be found, as well as defining the world of luxury and the rules of etiquette that governed Court life during the reign of Louis XIV and subsequent monarchs.

However, although we can find various forerunners of fashion publications in the eighteenth century, it was not until the twentieth century that fashion magazines became a popular and widespread feature within society. This development emerged, above all, in the United States, with the appearance of Harper's Bazaar (1867) and Vogue (1892). In 1913, Hearst purchased Harper's Bazaar, which became Vogue's main competitor throughout the first half of the twentieth century. Condé Nast acquired Vogue after its founder's death in 1909 and began to publish the magazine in the United Kingdom in 1916 and in France in 1924. The same publishing house created Vanity Fair in 1913, a publication that was relaunched in 1983.

The success of both magazines, Harper's and Vogue, coincided with economic boom periods in the United States. Furthermore, the publishers of Harper's $\mathrm{Ba}$ - zaar, first Carmel Snow and, in particular, Diana Vreeland, were able to endow the magazine with a certain touch of glamour and creativity. The key role of the editor was later inherited by Anna Wintour at Vogue in 1988, when she combined unknown models with renowned actresses, and "fast-fashion" brands with luxury brands. As of this moment a new approach to fashion communication was born.

The network of participants, characteristic of these magazines, such as stylists, editors, photographers and models, introduced a whole series of new players within the fashion world. Within the realm of photography, Newton, Pen and Avedon transformed the vision of fashion magazines during the first half of the twentieth century, whilst others such as Demarchelier, Testino and Outumuro transformed their outlook in the second half of the century. All of these figures shaped the development of fashion magazines, as we know them today (Casajus, 1993).

After the end of the Second World War, two French magazines also achieved considerable commercial success. First came Elle in 1948, and then Marie Claire reappeared with a new lease of life later on, both publications focusing on a new kind of modern woman who worked outside the home. These magazines managed to seduce the average reader and exercised a special influence when prêt-à-porter burst onto the scene in Europe.

In general, fashion publications target a type of reader who is more or less an expert in fashion. The spring issue (February/March) and the autumn issue (August/September) contain extensive editorials and often come with supplements showing the international collections that have been presented over the previous quarter at fashion shows. Only the large fashion houses and leading designers with financial clout plan their communication campaigns in these kinds of publication, given the high cost of including advertisements in fashion magazines.

These publications have the following functions: they (a) provide information to readers; (b) legitimize products for buyers - according to their importance, 
they play a part in selecting the textile samples and different models presented to clothes-makers (Rivière, 1977). In this manner, the trade knows when to make the purchase, given that the products will be supported by the fashion press; they (c) prescribe products and different ways of wearing them; and (d) provide advertising space for conventional ads, advertorials, clothes presented in showrooms, or what is known as the "Italian model." It is a systematic negotiation for the publication of informative photos in exchange for advertising pages; where the advertiser negotiates, for example, the appearance of 40 models in the editorial information in exchange for the inclusion of advertising for 80 models. The effectiveness of this tactic leaves the fashion editor somewhat impotent, given that he or she is unable to reflect his or her own taste or choice in terms of style, with the advertiser's marketing strategy taking precedence.

\subsubsection{Impact of digitalization on fashion magazines}

Today fashion magazines are beginning to question their role within the new digital environment, in the same manner in which the general-interest press has begun to question its own. In this respect, the re-invention of the fashion press has led to a more prominent role in other spheres, based on the following tendencies:

, Editors as celebrities and authorities. They have become more important than the magazines themselves, because the fashion editor has been enthroned as an authority within the field. Although Snow and Vreeland already possessed this authority, it was perhaps the novel and subsequent film of The Devil Wears Prada (2006) that established the fashion editor as the legitimizing figure for the industry. Subsequent documentaries, such as The September Issue (2009) by R.J. Cutler, HBO's production entitled In Vogue: The Editor's Eye (2012), and the more recent Mademoiselle $C$ (2013) by Fabien Constant have helped to create this halo and this fascination with fashion editors.
, Magazines are entering the fashion business itself by launching their own brands, such as ElleWomenswear in the summer of 2006.

, Incursions into parallel worlds in order to raise awareness and generate legitimacy, such as art and museums. One example of this strategy is provided by the MET Gala, annual event organized at the Metropolitan Museum of Art's Costume in New York city, which is linked to the Vogue magazine.

, And, of course, the creation of online magazines by fashion brands, such as Net-à-Porter.

The fact is that, with new technologies, fashion brands are able to broadcast their marketing messages without the intermediation of magazines. Many brands generate their own editorials and seem to have transformed themselves into another member of the communication media. This has not only occurred within the luxury segment, but companies such as Zara now editorialize their own web pages and compete with magazines in terms of quality and content. Brands have also begun to create their own visual contents with 'fashion films', a genre that offers endless possibilities and in which the leading film producers work with the brands to create high-quality worlds of visual content (Noguera \& Torregrosa, 2015).

\subsection{Fashion shows}

Another realm of communication that has witnessed significant changes are fashion shows. They have played an important role in fashion since Charles Frederick Worth (1825-1895) first presented its seasonal trends using models and featuring a certain degree of spectacle.

Originally designed for buyers and the press, shows are previews of collections that would hit stores six months later: buyers come to see the upcoming season's offerings and put in orders while fashion magazine editors use it to forecast trends and see what looks and pieces they want to feature in their publications. This also allows time for retailers to arrange to pur- 
chase or incorporate the designers into their retail marketing.

Four leading fashion centers (London, Milan, New York, and Paris) have been complemented by cities such as Tokyo, Buenos Aires and Madrid, whilst some 140 fashion weeks are estimated to take place throughout the world. Today, Miami and Dubai have emerged as up-and-coming fashion show centers. Some focus on specialist segments (menswear, swimwear, wedding fashion ...).

With the advent of digital technologies, fashion shows have witnessed numerous changes:

, Many brands have been able to shorten production times (for example, "fast fashion") and are thinking about reducing lead times, because otherwise they may lose their consumers' interest, who, in turn, may go and buy their designs from a brand that has been able to produce the trend faster.

, Consumers can access live-streams of most of the shows, which means that by the time the clothes actually hit the stores, they are not perceived as "new" anymore.

, Consumers want to buy things they see on the runway right away: "see now, buy now." As a result, "in-season collections" have begun to make an appearance. So these days, you might see winter clothing on the runway in September.

, The front row is not only packed with celebrities and members of the press, but also with bloggers who have replaced these figures, generating some considerable controversy regarding their role (Pedroni et al., 2017).

Bearing in mind these changes, it might seem that fashion shows are doomed to disappear. However, they continue to constitute a grand media event and have become increasingly spectacular (high-impact venues, Hollywood-style production, etc.). Furthermore, fashion centers have found that these fashion weeks bring great benefits to the cities in question (Kalbaska et al., 2018).
Within this new context, brands look around for alternative ways of raising awareness and reaching customers. They have found that the Internet and the social media offer them the possibility of generating their own contents without any need to turn to third parties. We could state that the new communication environment has created a key paradox. On the one hand, brands have become members of the media to the extent that their websites, videos and trading networks are now directly within reach of the audience. On the other, the same audience has gained greater control than ever over the messages that are generated and is capable of molding many contents according to its tastes. That is to say, that as brands have become more capable of generating direct messages, they have also lost control of the messages themselves.

In this respect, brands have become more subject to public scrutiny and more vulnerable to possible communication crises. Although knowledge of crisis management has progressed quite considerably (Pearson and Clair, 1998), this area constitutes one of the new communication fields in which fashion still has some work to do.

Following the fall-out of the Rana Plaza tragedy on the $24^{\text {th }}$ April 2013 (Sádaba \& Sanmiguel, 2014), we might state that a new communication field has emerged that revolves around management issues, focusing on aspects such as sustainability and social campaigns. Although the impact of issues of this kind is not clear amongst consumers (Mohr et al., 2001), such issues have begun to have a considerable effect on the rest of the stakeholders of fashion companies: employees, shareholders, regulators... In such cases, reputational aspects may not have much of an effect in the short term, but they do become important in the long term. And in this respect, communication, understood in its more strategic sense, once again seems to have a key role to play. 


\section{Digital transformation and fashion communication}

Fashion has started and is undergoing a major digital transformation, which is touching all its facets, layers, and processes (Rocamora, 2017). While we are focusing on communication-related aspects, it is important to briefly outline this digital transformation process in order to emphasize how communication is aligned and intertwined with all other aspects of a global process (Cantoni \& Danowski, 2015).

We could consider three different layers, where fashion interacts with information and communication technologies (ICTs) - which can be referred to, in a single word, as e-Fashion or "digital fashion":

1. ICTs are used to design, produce, and distribute fashion products;

2. ICTs impact marketing and sales;

3. ICTs are extensively used in communication activities with all relevant stakeholders, and contribute to co-creation in the fashion world.

These three layers of digital transformation and fashion communication are explained below.

First, ICTs are now playing a major role in the fashion industry, from the very sketching and designing of a fashion item (e.g. a piece of cloth or a pair of shoes), up to its production process and to the management of its distribution. ICTs do not only have accelerated such processes, making them more efficient, but have opened up new venues for business, as well as raised new challenges.

Second, both marketing as well as all other contacts with prospects and clients are extensively mediated or facilitated by ICTs. Digital technologies are more and more present in physical shops (e.g.: digital mirrors, augmented reality, tools for analytics etc.) and provide the main kernel that supports the fast emergence of eCommerce, as well as of other emerging business models (e.g.: exchanging or renting). More and more, players in the fashion domain need to work in an "omnichannel" way, that is, caring for clients across their complex journey through screens, publication and advertising outlets, virtual and physical touch points. These could be shops, printed and/or digital magazines, websites, mobile apps, newsletters, augmented reality applications, and many other things brands are experimenting and innovating with. In fact, also B2B marketing and internal communication - for instance training - are also leveraging on the extensive new opportunities offered by ICTs.

Third, the very processes through which something becomes fashionable or not, "in" or "out" are now happening increasingly online. Especially through social media, communities do negotiate online styles and trends, are exposed to influencers, share their reviews and opinions, as well as their own outfits. Such conversations are, at their turn, searchable and sharable, as well as open for companies and researchers to be listened to, in order to spot trends, interests, cultural differences ...

Communication studies and practices do address mainly the second and third levels. However, they have to constantly keep into consideration the first one, which is closely connected with them, in a circular way. For instance: an item can be fully designed through digital means and can be then displayed as dressed by a digital model (first level); it can be shared and promoted online (second level), in order to get feedback and to check the interest of intended audiences (third level). Depending on such feedback, it might be eventually produced and sold, or changed/ adapted, or discarded without any physical sampling (first level again).

Online Communication Model and its application to digital fashion.

When it comes to communication processes happening online, the Online Communication Model (Tardini \& Cantoni, 2015) can provide us with a useful map. This model helps companies to evaluate their existing online communication practices, measure the quality of their online communication and supporting technical tools, determine who their customers and 
users are, manage employees involved in digital communication, and also gain information about market and competitors.

The Online Communication Model distinguishes four main pillars and a fifth element, which are briefly introduced and applied to online communication in the fashion context. They are: (1) contents and functionalities; (2) technical tools; (3) people who manage digital communication; and (4) users and clients; and (5) information market/competitors.

\subsection{Contents and functionalities}

ICTs allow for multi-media content publication and high interactivity, offering endless opportunities to explore, vote, buy, customize, connect, share, exchange, copy, ask for and provide advice. Among the main communication issues we encounter here, one can list the following ones: information and communication quality; cultural translation (so-called localization) so to cater for different markets and cultures; the development of new genres needed by different distribution channels (e.g.: squared small size photos needed for Instagram, or Twitter texts, or 5 seconds of video-advertising).

The hybridization between physical and digital media requires constant adaptation and creativity: let us think of printed media connected with digital platforms via QR codes, or of interactive TV, or the endless opportunities offered by Augmented Reality or Mixed Realities to enrich the experience we have of fashion items.

\subsection{Technical tools that make available such contents and functionalities}

Second, how such contents and functionalities are made available through digital means has to be considered. This encompasses hardware and software, as well as the actual layout and information architecture, if we think of owned media (e. g.: official websites, mobile apps, newsletters). Here we should also address the strategic decision, about which contents/ functionalities should be offered through which publication outlet, be it an owned medium or an earned one - for instance, a social media platform, or a paid medium (e.g. a video campaign).

A range of opportunities, styles, and affordances can be seen here, in constant evolution. While at first, the default experience was being offline, and one had to go online, nowadays, we are experiencing exactly the opposite. The default is being constantly online, always connected via mobile devices, and we get offline either through an explicit decision (e.g.: in order to do some digital detox) or due to unfortunate events - loss of hardware, running out of a battery, lack of Wi-Fi or 3/4G coverage, exceeding of contractual data... In many cases, being offline is perceived as an un-happy of even painful experience, kind of lacking a major vital element, like oxygen. In fact, digital media are not any longer only a set of communication channels, but do constitute, more and more, the context of one's ordinary life.

In this area, while recognizing the huge developments of digital technologies, we should also remember that they are still quite limited, especially when it comes to communicating, supporting or enriching the sense of touch, so important when it comes to the experience of dressing something. Weight, contact with the skin, and temperature are definitely not (yet) captured by digital technologies. Even if we cannot predict that suitable technologies will be available on the market soon, we can still study how this lack does impact the way we approach fashion items, sometimes over-weighting their visual appearance over their actual physical structure. A similar discourse could be done about the sense of smell, when it comes to perfumes.

Technology is not only enabling fashion, but it is fashionable itself: wearable technologies and 3D printing are somewhere in between experiments and everyday practices.

Within major technological trends, we should mention here also the fields of (big) data analytics, and of Artificial Intelligence, being extensively deployed in order to better understand users' profiles, practices, and intentions to buy. Semantic technologies are also being applied to this 
field, in order to ensure a better re-use of information, as well as its retrieval.

\subsection{People who manage digital communication}

On one side, companies need to reach higher maturity levels about digital transformation and its implications for fashion communication. The space between awareness and a full integration of processes is large, and no shortcuts or prêt-àporter solutions are available. On the other side, higher education institutions need to open needed research lines and curricula, so to prepare the next generations to leverage on huge new opportunities and to cope with new challenges (Kalbaska \& Cantoni, 2019). This special issue seeks to be a contribution in this direction.

A close dialogue with practitioners is required, reflecting on good/best practices and aligning communication theories with social and economic trends. ICTs and their impact are not only the topic/subject to be studied and taught, they might constitute also a channel through which we learn and up-skill - think of relevant eLearning, Open Educational Resources, or Massive Open Online Courses (Kalbaska, 2018).

We do not want to ignore that, here, we see several ethical issues and challenges. A naïve approach to the industry, based on "the more the better" equation, has to be abandoned, in favor of a higher awareness of the importance of fashion in the construction itself of living styles and societal values, when it comes to mutual respect or to economic, environmental, or socio-cultural sustainability. Think, for instance, among the many issues, of the power of models to shape the image of a "nice body," or of the issue of using (big) data from clients when it comes to protecting their privacy. One should prepare to work in the field of Digital Fashion Communication with a great awareness of such responsibilities.

Such responsibility should also be requested from influencers, whose practices increasingly require transparence and a clear understanding of the interests at stake (not to mention the phenomenon of fake followers).

\subsection{Users and clients}

In fact, users and clients should be at the center of every communication practice or study. Communication happens not only through the mere expression and (broad) casting of messages, but only if they reach an addressee, and are somehow interpreted and understood. The digital transformation has opened up huge opportunities for customization not only of products and services, but also of communication itself. It has, moreover, demonstrated how the simple approach to the addressees as "targets" is no longer useful. Companies should not "target" prospects/clients, but nurture meaningful conversations with them, leveraging on digital communication not only to spread well-designed messages and offers, but also to create fine-tuned messages for each of them. First and most importantly, they need to listen to them. Digital analytics, supported both by high-touch and high-tech - for instance, by experts in argumentation to understand their main drivers, or by artificial intelligence to interpret main trends - are more and more needed to grow sustainable practices in the fashion domain.

\subsection{Information market/competitors}

As Semiotics and Linguistics have taught us, no sign lives in a vacuum: all signs do belong to systems, where the relationship with all other items helps to shape their different meanings and roles. Clothes, brands, designers, shows do belong to (i) paradigms - clusters of elements that are somehow interchangeable, because they can take the same role, and (ii) to syntagms - different combinations of paradigmatic elements. We can think of the paradigm of haute-couture brands vs. fast fashion ones, or of the syntagm of different clothes/apparels a person might wear for a meeting whose dress code is "business informal" vs. "casual."

Internet has made such relationships clearer and even more easily findable. Online, one can explore similar/opposite communication practices, compare of- 
fers and looks in a minute. Every change, aimed at re-structuring the overall system can be seen and can impact the market faster and deeper, due to the speed of online communication, where everything is just a click away. For industry players and researchers, online communication expands the access to innovations and amplifies its effects, while shortening and speeding up the innovation cycle. For users, we might see the same effect, which empowers them to access more info and offers, or an opposite one, where people might be locked within self-constructed information bubbles or echo-chambers, which limit their capacity of exploring or even just seeing alternatives and different styles.

\section{Mapping this special issue on Fashion Communication and its articles}

Once the many relationships between fashion and communication and the impact of digital transformation on both have been framed, it is time to map accepted papers to this special issue according to such a frame. The articles belonging to this special issue are presented in three sections: Fashion is (also) communication; Communication (media) and fashion-related industries and practices; Digital transformation and fashion communication.

\subsection{Fashion is (also) communication}

We are glad to start with a paper Il vestito forma la persona "clothes make the man": fashion morality in Italian nineteenth-century conduct books, by Paternoster and Saltamacchia, which discusses the relation between etiquette rules for dress and moral values. This research presents a detailed analysis of what fashion meant for Italian nineteenth-century etiquette books. While analyzing a corpus of influential conduct books, the authors apply current insights in the role of values for the emergence and maintenance of conventions developed within the pragmatics of politeness to the prescriptive discourse on fashion. The authors argue that fashion choices are always said to communicate moral values. In fact, most Italian conduct books in the nineteenth-century reinforce fashion norms by anchoring them in moral values because the authors expect their readers to be morally evaluated in terms of the clothes they wear. Researchers provide an overview of rules regulating bodily hygiene, adornment, dress choice and fashion, and analyze which values are explicitly cited to justify such rules. The manuscript, thus, is rich and appealing for those readers interested in the history and representation of fashion, and in its relationships with literature.

With the next contribution, we are staying within the European fashion context. The research by Ok - European Luxury Fashion Brand Advertising, and Marketing Relating to Nostalgia examines how European luxury fashion brands use nostalgia in their advertising \& marketing. This research, through a qualitative content analysis, identifies how nostalgia theme was used in the adverts from Vogue magazine. It provides an understanding of the themes, and an analysis of adverts in terms of luxury brand characteristics, narrative, and semiotics. Indeed, this contribution might be of interest for those studying luxury fashion advertising, brand heritage, emotional branding, and semiotics.

The third contribution in this section is by Lascity - Girls that Wear Abercrombie \& Fitch: Reading Fashion Branding Aesthetics into Music Videos. It should be of relevance of those studying fashion branding and mediated popular culture. The author investigates 42 music videos that appeared on MTV's Total Request Live, which contain elements of the "Abercrombie" lifestyle. This research suggests that music videos from the time were instrumental in spreading the brand's aesthetic, and that there is a strong interplay between media popular culture and the aesthetics of fashion brands. The author suggests that brand's marketing images could have been ripped from popular music videos (and vice versa), which helped drive Abercrombie \& Fitch's cultural influence and financial success. 
A different perspective to fashion communication is brought by Christel and Dunn. Their study: What Plus-Size Means for Plus-Size Women: A Mixed Methods Approach offers insights into how plus-size consumers view sizing communications. This study proposes a valuable ranking of terms that fashion companies can adopt to ensure they are communicating in a language that the intended consumers might prefer. This study contributes to research on social identity of clothing size, plus-size consumer experiences, and further validates the multidimensional challenges faced by plus-size consumers. It might be of use by both research communities interested in the retail strategy communication, consumer behavior, and fashion marketing, but also fashion companies working in the domain. Moreover, it helps to keep into consideration also the related ethical issues.

\subsection{Communication (media) and fashion-related industries and practices}

The article by von Wachenfeldt - Communicating Seduction: Luxury Fashion Advertisement in Video Campaigns will start the section of our special issue dedicated to the communication (media) and fashion-related industries and practices. She examines communication practices that take place in video ad campaigns deriving from five French luxury fashion houses, namely Louis Vuitton, Dior, Chanel, Cartier and Hermès. The semiotic method used enables her to recognize in videos the themes of adventure, seduction, love and playfulness. This study investigates also how the myth becomes an important meaning-maker of the luxury commodity, filled with sensations and pleasure. The author suggests that the objects of luxury constitute a strong communication tool, helping us to discover new places, to fall in love, to create magic, and to experience playfulness. Von Wachenfeldt concludes that embedded in recognizable social narratives, the objects in the moving image are provided with magical meaning able to support the eternal myth of luxury.
Video is one of the most powerful media channels in the fashion domain. We see it also with a research by Buffo - Body in Fashion Films: the Net-Aesthetics Era. With the term "fashion film" she refers to those online videos that are peculiar to the fashion industry and are developing their own language and new typologies of brand narration. The field of study presented here is related to language. In fact, the objective of this research is to better understand how this new communication tool has influenced the traditional language of fashion images by developing new codes or transforming existing ones. The object under examination is, in particular, the body as a preferred communication code in this industry. The body, according to Buffo, is not viewed by fashion as a simple object to dress, but as a mediating channel between the person's individuality and the need for communication, or rather, the need to establish a relationship within its context. The author examines the history of fashion images by focusing concisely on the analysis of how the body has changed its communicative role over the decades. Further analysis was then conducted focusing on the new meaning taken on by the body in fashion films. The result is a complex and extremely rich picture. Indeed, this contribution is of interest for those studying fashion films, visuals, and photography.

The article by Hibberd - Key Challenges for the Fashion industry in Tackling Climate Change, rises the topic of climate change, a major political, economic and social issue. One of the main industries when it comes to pollution is the fashion one, as every stage in the production of garments creates pollution and emission problems. The author examines broad attempts of using public campaigns, which include fashion involvement, to focus attention on climate change with particular attention paid to two popular British climate change initiatives. This research is based on interviews with climate change experts and those working within the campaigning industry, including 10:10 and the WWF's Earth Hour. The author suggests that the fashion industry can capitalize 
on its modern high-profile status to bring real attention to climate change and pollution issues through publicity and media attention. This article should be of interest among many others to those studying media management and sustainable fashion communication.

The article, which closes this section, by Matthews - Taste-making in turbulent times: Vogue and its social networks examines the evolution of taste-making practices in fashion communication. The contents from British Vogue May 1967 and May 2017 provide data for a comparative analysis of changing methods of influence in fashion. This qualitative case study considers how Vogue has responded to the networked conditions of the contemporary communication environment, and what its digital strategy can reveal about new methods of influence. It identifies how the ongoing structural changes to fashion communications continue to reshape institutional tastemakers such as Vogue, online and offline. This well structured and a clearly presented piece of work is relevant for the industry and the fashion communication research community at large.

\subsection{Digital transformation and fashion communication}

The articles belonging to the last section are examining the impact of the digital transformation on fashion communication. The first article, by Tuite - Communicating material characteristics in a digital age: three case studies in independent fashion, focuses on the intersection of the material and the digital in the independent fashion sector, with a focus on ways in which digital media and contemporary communication tools are being used to unite them. The researcher explores the tension between the opportunities provided to small businesses in the contemporary media landscape and its use in a sector closely associated with a nostalgic valorization of material qualities related to nature, artisanship, and luxury. This thematic analysis of online texts and images related to three contemporary American independent labels, finds that instead of being viewed as a threat to the inde- pendent fashion sector's driving ethos, technology has been embraced as a tool allowing independent fashion producers to amplify their voices as they challenge existing fashion paradigms.

The last two papers of this special issue deal with the emerging topic of fashion influencers. Both papers should be of interest for those researching brand communications, social networks, and the role of influencers. The paper by González-Fernández and Martínez-Sanz Fashion Influencers and Instagram. A quasi-perfect binomial explores communication strategies of main Spanish fashion bloggers in their Instagram profiles. In addition, compliance with Spanish legislation on advertising is monitored, which obliges the authors to explicitly indicate any message that promotes a product or service from a contractual agreement.

The closing contribution by SanMiguel, Guercini, and Sádaba - The impact of attitudes towards influencers amongst millennial and post-millennial fashion buyers identifies the way influencers affect the behavior of millennial buyers in the process of consuming fashion goods. The paper presents an extensive literature on opinion leaders, ranging from the origins of the concept to its developments within the context of the Internet. The shift from influential to influencer and the different types of influencer are examined and certain hypotheses regarding the role of influencers (including all the influential players) regarding fashion-buying millennials are examined.

In this introduction we provided a map of fashion communication, and a compass to navigate within it. It is now time for you to explore such fascinating territory, approaching the contributions collected in this issue of SComS.

We wish you an enriching and inspiring exploration! 


\section{References}

Alison, L. (1981). The language of clothes. An owl book. New York: Henry Holt.

Barthes, R. (1973). Système de la mode. Paris: Éd. Du Seuil.

Burke, P. (1995). La fabricación de Luis XIV (Vol. 1). San Sebastian: Editorial Nerea.

Cantoni, L., \& Danowski, J.A. (2015). Communication and Technology. Berlin: De Gruyter Mouton.

Casajus, C. (1993). Historia de la fotografía de moda. Unpublished PhD Thesis. Universidad Complutense de Madrid (Spain).

Davis, F. (1994). Fashion, culture, and identity. Chicago: University of Chicago Press.

Entwistle, J., \& Millet, A.S. (2002). El cuerpo y la moda: Una visión sociológica. Barcelona: Paidós.

Gladwell, M. (2000). The tipping point: How little things can make a big difference. Columbus: Little Brown.

Hebdige, D. (1988). Object as image: The Italian scooter cycle, material culture. Critical Concepts in the Social Sciences, 2, 121.

Jove, M. (2011). Influentials: localizando líderes de opinión en “El Confidencial." Pamplona: Eunate.

Kalbaska, N. (2018). Mapping e-learning courses in the fashion domain. In J. Li (Ed.), Fashion futures. $20^{\text {th }}$ Annual Conference for the International Foundation of Fashion Technology Institutes (pp. 426-433). Shanghai (China).

Kalbaska, N., Ayala, E., \& Cantoni, L. (2018). The role of tourism destinations within the online presence of fashion weeks. Almatourism - Journal of Tourism Culture and Territorial Development, 9(9), 87-114.

Kalbaska, N., \& Cantoni, L. (2019). Digital Fashion Competences: market practices and needs. In R. Rinaldi \& R. Bandinelli (Eds.), Business Models and ICT Technologies for the Fashion Supply Chain (pp. 125-135). Cham: Springer.

Keller, E., \& Berry, J. (2003). The influentials: One American in ten tells the other nine how to vote, where to eat, and what to buy. New York: Simon and Schuster.

Lazarsfeld, P. F., Berelson, B., \& Gaudet, H. (1944). The people's choice: How the voter makes up his mind in a presidential cam- paign. New York: Columbia University Press.

Lipovestky, G. (1987). L'Empire de l'éphémère: la mode et son destin dans les sociétés modernes. Paris: Gallimard.

Lotman, I. (2011). La moda es siempre semiótica. Revista de Occidente, 366, 107-117.

Mohr, L.A., Webb, D. J., \& Harris, K. E. (2001). Do consumers expect companies to be socially responsible? The impact of corporate social responsibility on buying behavior. Journal of Consumer Affairs, 35(1), 45-72. doi:10.1111/j.1745-6606.2001. tb00102.x

Noelle-Neumann, E. (1974). The spiral of silence. A theory of public opinion. Journal of communication, 24(2), 43-51. doi:10.1111/j.1460-2466.1974.tb00367.x

Noelle-Neumann, E. (1983). Persönlichkeitsstärke-Ein neues Kriterium zur Zielgruppenbeschreibung. SPIEGEL-Dokumentation: Persönlichkeitsstärke: Ein neuer Massstab zur Bestimmung von Zielgruppenpotentialen. Hamburg: Spiegel Verlag.

Noguera, M., \& Torregrosa, M. (2015). Los fashion films como relatos audiovisuales de marca. In T. Sadaba (Ed). Moda en el entorno digital (pp. 173-186). Pamplona: Eunsa.

Pearson, C., \& Clair, J. (1998). Reframing crisis management. Academy of Management Review, 23(1), 59-76. doi:10.5465/ amr.1998.192960

Pedroni, M., Sádaba, T., \& SanMiguel, P. (2017). Is the golden era of fashion blogs over? An analysis of the Italian and Spanish fields of fashion blogging. In E. Mora \& M. Pedroni (Eds.) Fashion Tales. Feeding the Imaginary (pp. 105-124). Bern: Peter Lang.

Riviere, M. (1977). La moda, ¿comunicación o incomunicación?. Barcelona: Editorial Gustavo Gili.

Rocamora, A. (2017). Mediatization and Digital Media in the Field of Fashion. Fashion Theory, 21(5), 505-522.

Sádaba, T., \& SanMiguel, P. (2014). Fashion on fire: responses on Bangladesh crisis. Actas IX Congreso Internacional de Moda: Digital Development in the Fashion Industry: Communication, Culture and Bussines, 141-151.

SanMiguel, P., Sádaba, T., \& Durán, S.B. (2017). El papel de la comunicación personal: en 
la difusión de nuevas tendencias de moda. In Del verbo al bit. Sociedad Latina de Comunicación Social, 2106-2137.

Simmel, G. (1923). Filosofía de la moda. Revista de occidente, 1, 42-66.

Tarde, G. (1890). Les lois de l'imitation. Paris: Félix Alcan.

Tardini, S., \& Cantoni, L. (2015). Hypermedia, internet and the web. In L. Cantoni \& J.A. Danowski (Eds.), Communication and Technology (pp. 119-140). Berlin: De Gruyter Mouton.

Ted, P., \& Lynn, P. (1978). Fashion and antifashion: An anthropology of clothing and adornment. London: Thames and Hudson.

Tungate, M. (2013). Fashion brands: Branding style from Armani to Zara. London: Kogan Page Publishers.

UNESCO (2003). Convention for the safeguarding of the intangible cultural heritage. Retrieved from https://ich.unesco.org/en/ convention 
